\title{
BMJ
}

\section{Effectiveness of early physiotherapy to prevent lymphoedema after surgery for breast cancer: randomised, single blinded, clinical trial}

\author{
María Torres Lacomba, professor of physiotherapy, ${ }^{1}$ María José Yuste Sánchez, professor of physiotherapy, ${ }^{1}$ \\ Álvaro Zapico Goñi, professor of obstetrics and gynaecology, ${ }^{1,2}$ David Prieto Merino, lecturer, ${ }^{3}$ Orlando \\ Mayoral del Moral, professor of physiotherapy, ${ }^{4}$ Ester Cerezo Téllez, research fellow, Elena Minayo \\ Mogollón, research fellow ${ }^{1}$
}

${ }^{1}$ Physiotherapy Department,

School of Physiotherapy, Alcalá de Henares University, E-28871 Alcalá de Henares, Madrid, Spain

2Príncipe de Asturias University Hospital, Alcalá de Henares, Madrid

${ }^{3}$ Medical Statistics Unit, Department of Epidemiology and Population Health, London School of Hygiene and Tropical Medicine, London

${ }^{4}$ Physiotherapy Department, Provincial Hospital, Toledo, Spain

Correspondence to: $\mathrm{M}$ Torres Lacomba maria.torres@uah.es

Cite this as: BMJ 2010;340:b5396 doi:10.1136/bmi.b5396

\section{ABSTRACT}

Objective To determine the effectiveness of early physiotherapy in reducing the risk of secondary lymphoedema after surgery for breast cancer. Design Randomised, single blinded, clinical trial. Setting University hospital in Alcalá de Henares, Madrid, Spain.

Participants 120 women who had breast surgery involving dissection of axillary lymph nodes between May 2005 and June 2007.

Intervention The early physiotherapy group was treated by a physiotherapist with a physiotherapy programme including manual lymph drainage, massage of scar tissue, and progressive active and action assisted shoulder exercises. This group also received an educational strategy. The control group received the educational strategy only.

Main outcome measure Incidence of clinically significant secondary lymphoedema ( $>2 \mathrm{~cm}$ increase in arm circumference measured at two adjacent points compared with the non-affected arm).

Results 116 women completed the one year follow-up. Of these, 18 developed secondary lymphoedema (16\%): 14 in the control group (25\%) and four in the intervention group $(7 \%)$. The difference was significant $(\mathrm{P}=0.01)$; risk ratio 0.28 (95\% confidence interval 0.10 to 0.79 ). A survival analysis showed a significant difference, with secondary lymphoedema being diagnosed four times earlier in the control group than in the intervention group (intervention/control, hazard ratio $0.26,95 \%$ confidence interval 0.09 to 0.79 ).

Conclusion Early physiotherapy could be an effective intervention in the prevention of secondary lymphoedema in women for at least one year after surgery for breast cancer involving dissection of axillary lymph nodes.

Trial registration Current controlled trials ISRCTN95870846.

\section{INTRODUCTION}

Acquired interruption or damage to the axillary lymphatic system after surgery or radiotherapy for breast cancer can lead to regional or generalised accumulation of lymph fluid in the interstitial space, known as secondary lymphoedema. ${ }^{1}$ This condition is the most important chronic complication after dissection of the axillary lymph nodes ${ }^{2-5}$ and has a tendency to progress. Secondary lymphoedema can cause disfigurement, physical discomfort, and functional impairment. Anxiety, depression, and emotional distress are more common in patients with than without secondary lymphoedema. This can affect social relationships, undermining body image and self esteem. ${ }^{6-8}$ The condition may also precipitate cellulitis, erysipelas, lymphangitis, and occasionally lymphangiosarcoma. ${ }^{9-11}$

Reported incidence rates for secondary lymphoedema vary depending on the method used for measurement. ${ }^{12}$ Inconsistent definitions and the lack of a standard classification system have resulted in diverse incidence rates for secondary lymphoedema, ranging from $5 \%$ to $56 \%$ within two years after surgery. ${ }^{73-16}$ After axillary lymph node dissection the incidence of secondary lymphoedema is about $23-38 \%$ if the criterion used to identify it is a greater than $2 \mathrm{~cm}$ increase in upper arm circumference measured at two adjacent points compared with the circumferences in the other arm. ${ }^{17}$ Most women (71\%) develop secondary lymphoedema within 12 months after surgery for breast cancer. ${ }^{18} 19$

The factors that might influence the development of secondary lymphoedema after surgery are the number of lymph nodes removed, radiotherapy to the axilla, postoperative wound infection, postsurgical drainage time, lack of mobility, and obesity. ${ }^{1820-24}$

Currently, women with breast cancer have a $77 \%$ probability of surviving at least 10 years. ${ }^{2526}$ Consequently the effective prevention and management of complications that can impair function and affect quality of life after treatment are important. ${ }^{15}$

Efforts have been made to reduce the risk of secondary lymphoedema by preoperative and postoperative counselling and education ${ }^{2728}$ and by early detection. $^{2729} \mathrm{~A}$ randomised clinical trial on the 
prevention of secondary lymphoedema through exercises and an educational strategy, however, lacked sufficient evidence. ${ }^{30} \mathrm{We}$ determined the effectiveness of an early physiotherapy programme in reducing the risk of secondary lymphoedema in women after surgery for breast cancer involving dissection of axillary lymph nodes.

\section{METHODS}

We carried out a randomised, single blinded, clinical trial of women after unilateral breast cancer surgery with axillary lymph node dissection at the Príncipe de Asturias Hospital in Madrid between May 2005 and June 2007. We excluded women without axillary lymph node dissection or with bilateral breast cancer, systemic disease, locoregional recurrence, or any contraindication to physiotherapy.

Eligible women gave written informed consent to participate in the study after breast cancer had been confirmed by biopsy. Each participant was assessed preoperatively and between days 3 and 5 after hospital discharge. Equal numbers of women were then randomly allocated by computer using EPIDAT version 3.1 (Xunta de Galicia, Spain) ${ }^{31}$ to either early physiotherapy and an educational strategy (early physiotherapy group) or the educational strategy only (control group). Both programmes lasted three weeks, with three visits each week. The main outcome was the incidence of secondary lymphoedema.

\section{Follow-up}

Initially we scheduled four follow-up visits: four weeks after surgery (shortly after the completion of the intervention) and three, six, and 12 months after surgery. These dates were, however, flexible, depending on the participant's availability. At all visits lymphoedema was assessed using the same protocol.

If patients experienced pain, discomfort, or any other symptoms, they could contact the physiotherapist and a visit would be arranged. If secondary lymphoedema was diagnosed then complex decongestive physiotherapy was carried out, ${ }^{32-34}$ which would effectively interrupt follow-up.

\section{Interventions}

Each group had one physiotherapist, who carried out all interventions. Before the study it was agreed that both groups would receive the same educational intervention. The physiotherapists had more than five years' experience in the treatment of vascular diseases using lymphatic drainage. They were the only study members aware of group allocation.

Early physiotherapy group-The intervention included the manual lymph drainage technique used for the treatment of postoperative oedema (thorax, breast, axilla, and upper arm of affected side), using a modification of the strokes described by Leduc (only resorption strokes were used $)^{32}{ }^{34}$; progressive massage of the scar (progressing from Jacquet and Leroy pincer to Wetterwald pincer ${ }^{32}{ }^{35}$; stretching exercises for levator scapulae, upper trapezius, pectoralis major, and medial and lateral rotators muscles of the shoulder ${ }^{36}$; and progressive active and action assisted shoulder exercises, started in conjunction with functional activities and proprioceptive neuromuscular facilitation exercises without resistance (rhythmic initiation progressing from passive to active-assistive to active movement in two diagonal symmetrical bilateral patterns and asymmetrical reciprocal patterns: D1 into flexion from hitch hike to swat fly, and into extension from swat fly to hitch hike, and D2 into flexion from hand in opposite pocket to carry tray, and into extension from carry tray to hand in opposite pocket). ${ }^{37}$ If axillary web syndrome was diagnosed the physiotherapy protocol extended the manual lymph drainage technique to axilla and to proximal ipsilateral arm and included specific thumb manual lymph drainage on the characteristics taut cords, to make them gradually more flexible. The early physiotherapy group also did shoulder exercises and stretching at home once daily during the three week intervention period.

Educational strategy (both groups)-The educational strategy consisted of instruction with printed materials about the lymphatic system, concepts of normal load versus overload, the source of secondary lymphoedema, the identification of possible precipitating factors, and the four categories of interventions to prevent secondary lymphoedema (avoidance of trauma or injury, prevention of infection, avoidance of arm constriction, and use and exercise of the arm), ${ }^{27283839}$ together with individual strategies for implementing these measures.

\section{Assessments}

A different physiotherapist did the two initial and four follow-up assessments of all participants and remained blinded to group allocation. Participants were instructed not to reveal their allocation.

Lymphoedema-Direct measurement of the presence and severity of lymphoedema is difficult and different diagnostic criteria have been described, including comparison between preoperative and postoperative measurements within the affected arm and comparison of measurements between the affected and unaffected arms. ${ }^{162940-43}$ For our main analysis we used the criteria stated in the trial protocol-that is, a $2 \mathrm{~cm}$ or greater increase in the circumference of any two adjacent points compared with measurements in the other arm. ${ }^{194144-46}$ We also carried out the analysis using other criteria (data not shown).

Arm measurements - Whatever the criteria used for diagnosing lymphoedema they are all based on changes in size or volume of the arms. Arm circumferences were measured at each visit and always following the same procedure, using a standard $1 \mathrm{~cm}$ wide, retractable, fibreglass tailor's tape measure (Babel, Spain). With the patient in an upright sitting position with both arms on a table, shoulders in neutral rotation and flexion of $45^{\circ}$, and forearms at maximum supination, we measured the circumference at $5 \mathrm{~cm}$ intervals along both arms, using the elbow fold as the reference starting point. This has been reported as a valid and 


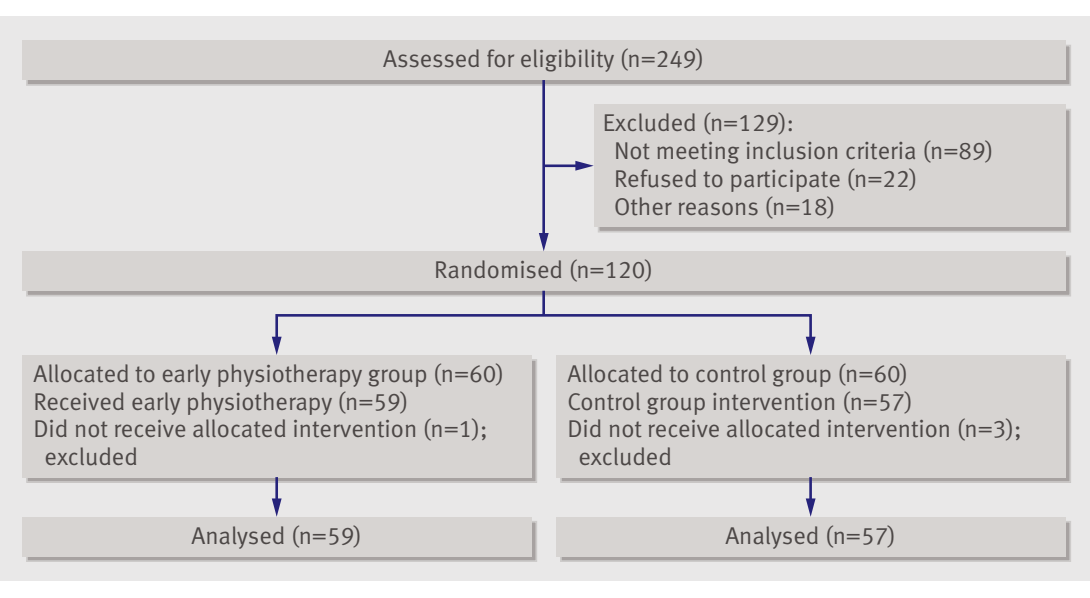

Fig 1| Progress of participants through study

reliable method for accurately quantifying and diagnosing secondary lymphoedema. ${ }^{47-49}$

Other variables -During the preoperative assessment we collected personal data on the participants, including age, ethnicity, marital status, body mass index, job, educational level, socioeconomic status, information on breast cancer, and medical history. In postoperative assessments, data were collected on the type of surgery done, the number of lymph nodes removed, the use of adjuvant treatment, and the development of seroma and infection. Participants were also asked an open question about whether they had any pain. If they did, a physical examination was carried out to find the source, including axillary web syndrome. The diagnostic criteria for axillary web syndrome were pain and restriction of range of motion in the shoulders, with

Table 1|Comparison between randomised groups at baseline. Values are numbers (percentages) unless stated otherwise

\begin{tabular}{|c|c|c|c|}
\hline Variables & $\begin{array}{l}\text { Sample } \\
(n=120)\end{array}$ & $\begin{array}{l}\text { Early physiotherapy } \\
\text { group }(n=60)\end{array}$ & $\begin{array}{l}\text { Control group } \\
(n=60)\end{array}$ \\
\hline Mean (SD) age (years) & $52.9(11.6)$ & $52.9(10.7)$ & $52.9(12.5)$ \\
\hline Mean (SD) body mass index & $27.0(5.1)$ & $27.9(5.6)$ & $26.2(4.5)$ \\
\hline Mean (SD) volume ratio at baseline* & $1.002(0.04)$ & $1.004(0.05)$ & $0.999(0.03)$ \\
\hline Mean (SD) maximum circumference $†$ & $0.45(0.62)$ & $0.54(0.71)$ & $0.37(0.51)$ \\
\hline In employment & $48(40)$ & $23(38)$ & $25(42)$ \\
\hline \multicolumn{4}{|l|}{ Surgical procedure: } \\
\hline Quadrantectomy & $50(42)$ & $24(40)$ & $26(43)$ \\
\hline Modified mastectomy & $43(36)$ & $23(38)$ & $20(34)$ \\
\hline Lumpectomy & $27(22)$ & $13(22)$ & $14(23)$ \\
\hline Mean (SD) No of dissected lymph nodes & $13.6(5.2)$ & $13.6(5.1)$ & $13.6(5.4)$ \\
\hline Mean (SD) No of days of drainage & $4.3(2.1)$ & $4.1(1.6)$ & $4.5(2.5)$ \\
\hline Seroma & $33(28)$ & $16(27)$ & $17(28)$ \\
\hline Wound infection & $11(9)$ & $6(10)$ & $5(8)$ \\
\hline Axillary web syndrome after surgery & $55(46)$ & $26(43)$ & $29(48)$ \\
\hline Postoperative therapy $\ddagger$ & $(n=116)$ & $(n=59)$ & $(n=57)$ \\
\hline Radiotherapy & $93(80)$ & $44(75)$ & $49(86)$ \\
\hline Chemotherapy & $95(82)$ & $50(85)$ & $45(79)$ \\
\hline Hormonal therapy & $72(62)$ & $39(66)$ & $33(58)$ \\
\hline
\end{tabular}

*Volume of affected arm to that of unaffected arm.

†Maximum difference measured between two adjacent points.

fExcludes four patients lost to follow-up: three in early physiotherapy group and one in control group. associated visible or palpable taut cords of tissue in the axilla in maximal shoulder abduction. ${ }^{50-54}$ Other secondary outcomes were measured according to the protocol but are not reported here.

\section{Statistical analysis}

The clinical criterion we chose to determine lymphoedema (binary variable) was based on changes in circumference along the arm (continuous variable). The raw data are therefore measures of circumference. To obtain the binary outcome several intermediate variables need to be computed from these measurements (see web extra on bmj.com). The important variable here would be the maximum difference in arm circumference between any two adjacent points. A patient would have a diagnosis of secondary lymphoedema if the maximum difference between any two adjacent points was $2 \mathrm{~cm}$ or greater. Lymphoedema can also be determined from the increase in volume ratio of both arms (volume of affected arm divided by volume of unaffected arm). ${ }^{293042445556}$ The volume ratio is computed in the variable "change in volume ratio" (presented as percentages). Although we chose not to use this as part of our criteria for clinical diagnosis we include a continuous analysis on this variable. This variable can be easily interpreted as an increase or decrease of the proportional difference of the volumes of both arms (affected minus unaffected; see web extra on bmj.com). Total arm volume was calculated by adding up all the partial volumes between every two adjacent measurements. Each of these partial volumes was calculated by an approximation to a truncated cone with the formula:

\section{$\mathrm{V}=\mathrm{D}\left(\mathrm{C}_{1}{ }^{2}+\mathrm{C}_{2}{ }^{2}+\mathrm{C}_{1} \mathrm{C}_{2}\right) / 12 \pi$}

where $\mathrm{C}_{1}$ and $\mathrm{C}_{2}$ are the circumferences and the two adjacent locations and $\mathrm{D}$ is the distance between $\mathrm{C}_{1}$ and $\mathrm{C}_{2}$. We have not included hand volume as this is difficult to model with a truncated cone. Truncated cone calculations of limb segment volumes using the circumference of segments have been reported to be reliable. ${ }^{16}$

\section{Power calculations and sample size}

Although the sample size was limited by patients' availability we did some power calculations. With this sample size and after 3\% of dropouts, we would have a power of $70 \%$ to detect a difference of $20 \%$ in the incidence of secondary lymphoedema between the groups. This assumes an incidence of 30\% in the control group (according to findings in earlier studies $^{16171944}$ ) and setting a type I error of 0.05 .

Statistical analyses were done using Stata version 10.0. ${ }^{57}$ For the primary analysis we compared the groups in three ways. Firstly, we used a binary outcome analysis to compare the incidence of lymphoedema, determined according to the chosen criteria. Secondly, we used a continuous outcome analysis to compare the variables "maximum difference in arm circumference between two adjacent locations" and "change in volume ratio." Thirdly, as we had recorded the timing of diagnosis of lymphoedema we carried out a survival 
Table 2 |Comparison of secondary lymphoedema in groups

\begin{tabular}{|c|c|c|c|c|}
\hline Group & $\begin{array}{l}\text { Early physiotherapy } \\
\text { group }(n=59)\end{array}$ & $\begin{array}{l}\text { Control group } \\
\qquad(n=57)\end{array}$ & $\begin{array}{l}\text { Odds ratio } \\
(95 \% \mathrm{Cl})\end{array}$ & $P$ value \\
\hline No (\%) with lymphoedema & $4(7)$ & $14(25)$ & & \\
\hline Early physiotherapy $v$ control* & 0.28 (0.10 to 0.79$) \dagger$ & - & $0.22(0.07$ to 0.73$)$ & 0.010 \\
\hline Early physiotherapy $v$ control & - & - & $0.22(0.07$ to 0.72$)$ & 0.013 \\
\hline
\end{tabular}

*Crude effect.

†Risk ratio (95\% confidence interval).

$\ddagger$ Adjusted for body mass index. ratio $0.26,95 \%$ confidence interval 0.09 to 0.79 ; $\mathrm{P}=0.010)$. The shape of the failure curves (1 minus survival) suggests that the protective effect of early physiotherapy remained for a long time, whereas the proportion of patients with a diagnosis of secondary lymphoedema in the control group increased progressively (fig 4).

\section{DISCUSSION}

Early physiotherapy with an educational strategy after surgery for breast cancer that involved dissection of axillary lymph nodes was associated with a lower risk of secondary lymphoedema than the educational strategy only (control group) after 12 months of follow-up: $25 \%$ in the control group compared with $7 \%$ in the intervention group. Secondary lymphoedema developed from six to 12 months postoperatively, which agrees with previous studies. ${ }^{2930}$ This could be due to the sum of various risk factors associated with secondary lymphoedema: axillary lymph node dissection, the number of lymph nodes removed (between 10 and 20 nodes were removed in 17 of the 18 women with secondary lymphoedema), overweight (12 of the 18 women had a body mass index $>25$ ), and postoperative complications (all 18 women had postoperative complications) along with the effect of radiotherapy (completed in the fourth postoperative month) as well as the gradual weight gain (11 of 12 women with secondary lymphoedema who were overweight at baseline progressively increased in weight from six months after surgery). ${ }^{1820212324}$ Further investigation of these risk factors is needed.
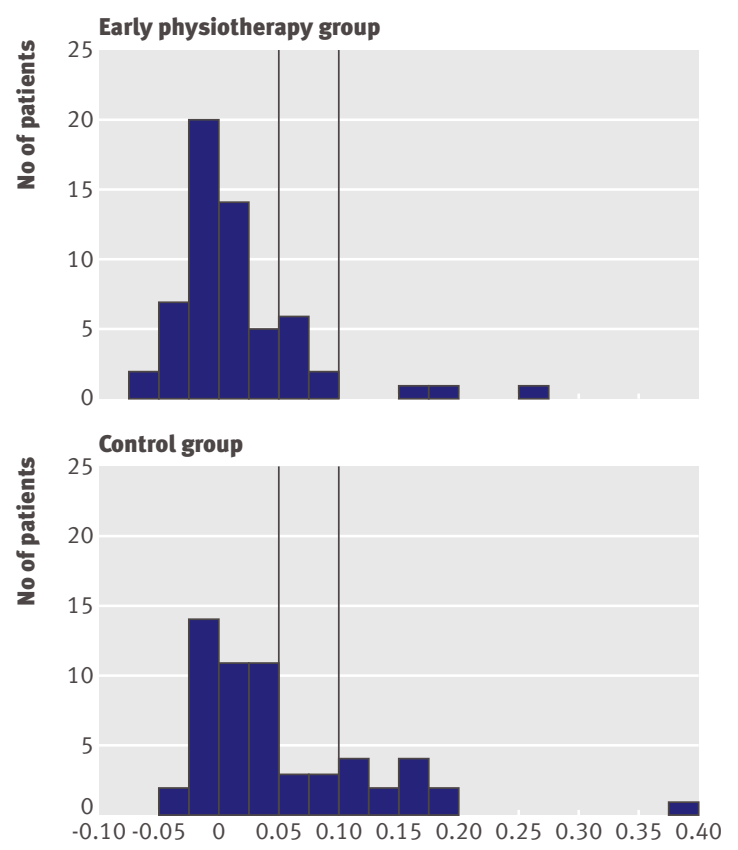

(Ratio at 12 month visit) - (ratio at preoperative visit)

Fig 2 | Increase in volume ratios between arms. Vertical lines correspond to cut-off values for diagnoses of lymphoedema in other studies ( $>5 \%$ and $>10 \%$ increase) 
Table $3 \mid$ Continuous analysis of circumferential and volume measurements. Values are means (standard deviations) unless stated otherwise

\begin{tabular}{|c|c|c|c|c|}
\hline Measures & Follow-up & $\begin{array}{l}\text { Early physiotherapy } \\
\text { group }(n=59)\end{array}$ & $\begin{array}{l}\text { Control group } \\
\quad(n=57)\end{array}$ & P value* \\
\hline Change in volume ratio & Baseline to 12 months & $1.6(5.6)$ & $5.1(7.6)$ & 0.0065 \\
\hline Maximum circumference $\dagger$ & 12 months & $0.68(0.91)$ & $1.15(1.21)$ & 0.0207 \\
\hline
\end{tabular}

Secondary lymphoedema is thought to be caused by damage to the axillary lymphatic system, impairing lymph drainage from the arm, although there is strong evidence that total blood flow in the arm and vascular bed size are increased in secondary lymphoedema. ${ }^{1}$ Recently, a study to develop an animal model of postsurgical lymphoedema reported that after nodal excisions the limbs became progressively more oedematous up to three days after node dissection and that the swelling decreased but had not resolved 16 weeks after surgery. ${ }^{58}$ Taking this into account and since the basic rule is that all oedemas result from an imbalance between filtration and resorption (tissue drainage), the implementation of a measure to restore this balance during the period of higher filtration should prevent or delay the onset of secondary lymphoedema. Our study included manual lymph drainage, which is a special method involving gentle massage to improve the lymph circulation, especially subcutaneous circulation, to stimulate the initial lymphatics, and to stretch the lymph vessels, consequently improving the removal of interstitial fluid. Manual lymph drainage encourages and improves resorption without increasing filtration. ${ }^{3459}$ It has been shown to be effective in the treatment of lymphoedema because it improves the removal of fluid from interstitial space. ${ }^{32345960}$ We therefore think that the implementation of manual lymph drainage after surgery for breast cancer in the early physiotherapy group could have contributed to the better results in that group. This, together with early physiotherapy for other effects of breast cancer surgery, and related to the onset of secondary lymphoedema, ${ }^{1820212324}$ could explain the effectiveness of early physiotherapy in the prevention of secondary lymphoedema in women who have had surgery for breast cancer with axillary lymph node dissection - at least during the first year after surgery.

We also found that 12 of the 18 women who developed secondary lymphoedema had axillary web syndrome during the second and third week after surgery. The axillary web syndrome is a known but poorly studied complication of surgery. ${ }^{546162}$ No study has shown any link between the axillary web syndrome and the onset of secondary lymphoedema. We and others $^{3250}$ suggest that the axillary web syndrome may be a sign of injury to the lymphatic system and it could produce a lymphatic overload as a result of failure of the lymphatic system. This overload, together with other factors, could be responsible for the onset of secondary lymphoedema. When axillary web syndrome was diagnosed in the postoperative period in the intervention group, specific manual lymph drainage strokes were applied, together with progressive active and action assisted shoulder and arm exercises. Manual lymph drainage acted on the pain and inflexibility inherent to the vascular inflammation of the lymphatic vessel; also, if the axillary web syndrome did produce a lymphatic overload, and therefore a possible subclinical oedema, the action of the manual lymph drainage could help with reabsorption. ${ }^{3234596063}$ Further research on a possible relation between the axillary web syndrome and the development of secondary lymphoedema in women after breast cancer surgery is needed.

\section{Comparison with other studies}

Secondary lymphoedema is a common complication of breast cancer surgery. ${ }^{2-5}$ As far as we are aware, only one study has examined the effect of exercise and specific recommendations about self care to minimise the onset of secondary lymphoedema. ${ }^{2930}$ In addition, several studies on the effectiveness of early rehabilitation after breast surgery reported data on lymphoedema as secondary end points. ${ }^{64-68}$ Box and colleagues evaluated an intervention to minimise postoperative lymphoedema in 65 women and stated that a physiotherapy management care plan, including exercise strategies that were not described in the paper, and progressive educational strategies may reduce the occurrence of secondary lymphoedema two years after surgery. ${ }^{30}$ Our results for onset of secondary lympho-
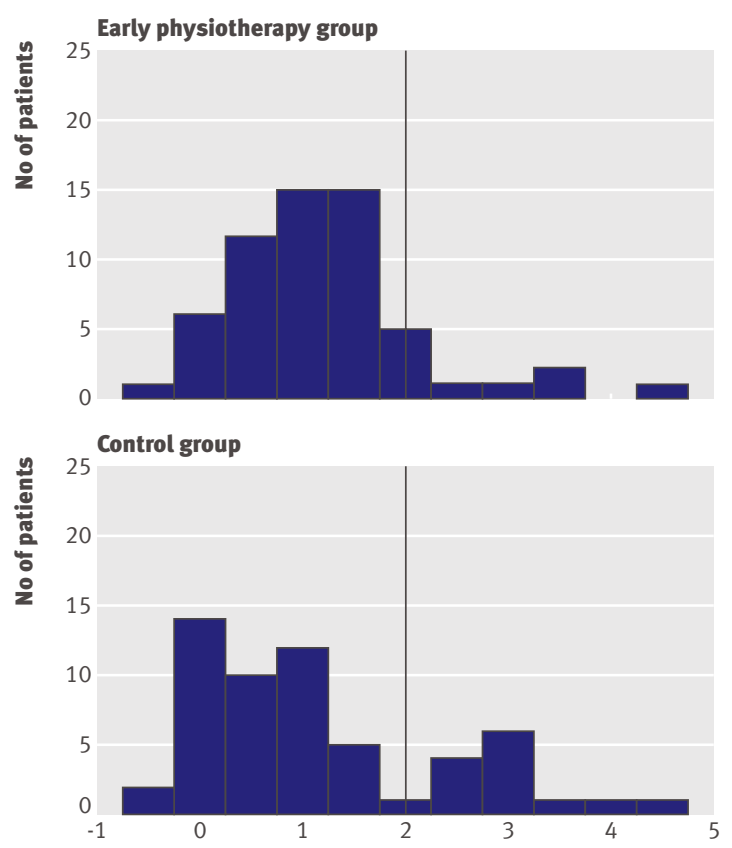

Maximum increase in arm circumference at two adjacent points (cm)

Fig 3| Maximum increase in arm circumference (affected arm - unaffected arm) that could be observed at least at two adjacent points. Vertical line corresponds to binary criteria used here to diagnose lymphoedema-that is, a $2 \mathrm{~cm}$ or greater increase in arm circumference observed at least at two adjacent points in affected arm compared with unaffected arm 


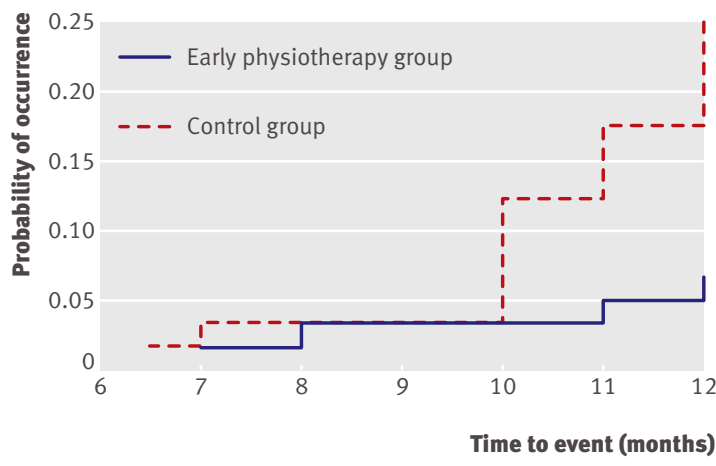

Fig 4 | Failure time for development of secondary lymphoedema by group

edema one year after surgery are better than their results. Exercise is used in the management of secondary lymphoedema of the arm to promote the recruitment of collateral lymphatics pathways. ${ }^{69}$ This might explain the difference in results between the studies. The intervention programme in the study by Box and colleagues did not include the diagnosis and treatment of postoperative vascular complications (such as seroma and axillary web syndrome), which could be related to the onset of lymphoedema and could benefit from a proper manual physiotherapy. ${ }^{50-53}$

Many studies have assessed the effectiveness of rehabilitation in patients after breast cancer surgery. ${ }^{64-68}$ All of them present limitations in the sample size and assert that physiotherapy is beneficial for shoulder mobility and functional capacity without causing adverse effects in the postoperative period, but not in preventing secondary lymphoedema. All the studies focused on the recovery or maintenance of the mobility of the shoulder so that the intervention was based on mobility and stretching exercises of the shoulder. ${ }^{64-68}$ Only one study included massage (not manual lymph drainage) in one of the intervention groups. This group showed better results, but the onset of lymphoedema was not prevented. ${ }^{65}$ The development of restricted shoulder mobility is one of the most important factors impairing functional activities of patients after breast surgery. ${ }^{70} \mathrm{~A}$ delayed onset physiotherapy programme as required has been suggested to improve shoulder mobility and daily activities of living. ${ }^{71}$ None of these studies could

\section{WHAT IS ALREADY KNOWN ON THIS TOPIC}

Secondary lymphoedema is the most important chronic complication after breast cancer surgery with dissection of axillary lymph nodes

Early postsurgical rehabilitation improves shoulder mobility and functional capacity without causing adverse effects but does not prevent secondary lymphoedema

\section{WHAT THIS STUDY ADDS}

Early physiotherapy with an educational strategy compared with the educational strategy alone was associated with a lower risk of secondary lymphoedema 12 months after surgery for breast cancer with axillary node dissection

The axillary web syndrome was an important complication in the immediate postoperative period correlate the exercise programme with the incidence of lymphoedema. ${ }^{64-68}$ Our results in relation to the study by Box and colleagues ${ }^{30}$ could result from the early diagnosis and treatment of postoperative vascular complications.

Strengths and limitations of the study

We believe that our study shows evidence of the positive effect of early physiotherapy in the prevention of secondary lymphoedema, but the study is limited by the duration of follow-up (one year after surgery) and recruitment in just one hospital. Although we have no reason to suspect systematic differences in care provided by this hospital and other regional hospitals or hospitals in other developed countries, this may limit the external validity of the results. Furthermore, that the physiotherapy was provided by trained physiotherapists may limit the generalisability of this intervention to other settings.

Another limitation is that we chose a particular criterion for diagnosing lymphoedema. We followed the criterion specified in our protocol but other criteria could have been used. For example, if the criterion of a greater than $10 \%$ increase in the volume ratio between arms (affected $v$ unaffected) had been chosen, the patients with a diagnosis of secondary lymphoedema would be those appearing to the right of the vertical line furthest to the right in figure 2. Using this criterion the early physiotherapy group would have three cases (5\%) and the control group 13 (23\%), with a risk ratio of $0.22(95 \%$ confidence interval 0.06 to $0.74)$; results similar to those in table 2 .

A further limitation is the possibility of measurement errors. We have no reason to believe, however, that this will have a differential effect on both intervention and control groups. The physiotherapist who took the measurements was blinded to the patient's treatment allocation. Both groups were reasonably balanced for baseline characteristics. The use of ratios between arms also reduces errors that could be correlated with some patient characteristics, such as body mass index. In general, we believe that measurement error might have the effect of slightly increasing the variance in the measurement, but not in a biased way. At the most, this would reduce statistical power of the comparisons to identify differences but would not invalidate the ones observed.

\section{Conclusion}

Early physiotherapy could help to prevent and reduce secondary lymphoedema in patients after breast cancer surgery involving dissection of axillary lymph nodes, at least for one year after surgery. This result emphasises the role of physiotherapy in the awareness, prevention, early diagnosis, and treatment of secondary lymphoedema.

Secondary lymphoedema is a chronic condition, which has negative effects on the quality of life of patients. The increase in risk factors associated with secondary lymphoedema, such as ageing populations and the growing prevalence of obesity, ${ }^{182224}$ along with 
the gradual improvement in rates of survival from cancer, ${ }^{26}$ suggest that secondary lymphoedema will remain a challenge. Further studies are needed to clarify whether early physiotherapy after breast cancer surgery can remain effective in preventing secondary lymphoedema in the longer term.

We thank the staff and patients of the Gynecology Service of Príncipe de Asturias University Hospital (Madrid), the Physical Therapy Research Unit at Alcala University (Madrid), and Jean Claude Ferrandez for their valuable suggestions. The Physical Therapy Department of Alcalá University and Principe de Asturias Hospital provided the facilities for the study. Contributors: MTL conceived and designed the study. AZG recruited the patients. MTL (blinded assessor), ECT, EMM (physiotherapy and educational strategies in the early physiotherapy group), and MJYS (educational strategies in control group) devised the interventions. DPM (blinded analyst), MTL, and OMdM analysed and interpreted the data. OMdM collected and assembled the data. MTL, OMdM, and DPM wrote the manuscript. All authors approved the final manuscript.

Funding: This study was funded by the Health Institute Carlos III (Protocol PI071124) of the Spanish Health Ministry.

Competing interests: All authors have completed the unified competing interest form at www.icmje.org/coi_disclosure.pdf (available on request from the corresponding author) and declare (1) no financial support for the submitted work from anyone other than their employer; (2) no financial relationships with commercial entities that might have an interest in the submitted work; (3) no spouses, partners, or children with relationships with commercial entities that might have an interest in the submitted work; and (4) no non-financial interests that may be relevant to the submitted work.

Ethical approval: This study was approved by the human research ethics committee of the Príncipe de Asturias Hospital.

1 Mortimer P. Pathophysiology of lymphoedema. In: Progress in lymphology. Jimenez Cossio, 1998:36.

2 Cheville A, Tchou J. Barriers to rehabilitation following surgery for primary breast cancer. J Surg Oncol 2007;95:409-18.

3 Batiston A, Santiago S. Fisioterapia e complicacoes fisico-funcionais apos tratamento cirurgico do cancer de mama. Fisioterapia e Pesquisa 2005;12:30-4.

4 Kitamura Y, Ohno Y, Kasahara S, Murata K, Sugiyama H, Oshima A et al. Statistical estimation of the number of breast cancer patients with disabilities resulting from surgery. Breast Cancer 2005;12:130-4

5 Nesvold I, Dahl A, Løkkevik E, Marit Mengshoel A, Fosså S. Arm and shoulder morbidity in breast cancer patients after breast-conserving therapy versus mastectomy. Acta Oncol 2008;47:835-42.

6 Beaulac S, McNair L, Scout T, LaMorte W, Kvanah M. Lymphedema and quality of life in survivors of early stage of breast cancer. Arch Surg 2002;137:1253-7.

7 Kwan W, Jackson J, Weir L, Dingee C, McGregor G, Olivotto I. Chronic arm morbidity after curative breast cancer treatment: prevalence and impact on quality of life. J Clin Oncol 2002;20:4242-8.

8 Rietman J, Dijkstra P, Debreczeni R, Geertzen J, Robinson D, Vries J. Impairments, disabilities and health related quality of life after treatment of breast cancer: a follow-up study 2.7 after surgery. Disabil Rehabil 2004;26:78-84.

9 Liu N. Trafficking of hyaluronan in the interstitium and its possible implications. Lymphology 2004;37:6-14.

10 Masmoudi A, Maaloul I, Turki K, Elloumi Y, Marrekchi S, Bouassida S, et al. Erysipelas after breast cancer treatment (26 cases). Dermatology Online Journal 2004:12.

11 Ocana A, Delgaco C. Case 3. Upper limb lymphangiosarcoma following breast cancer therapy. I Clin Oncol 2006;24:1477-8.

12 Hayes S, Cornish B, Newman B. Comparison of methods to diagnose lymphoedema among breast cancer survivors: 6-month follow-up. Breast Cancer Res Treat 2005;89:221-6.

13 Ozaslan C, Kuru M. Lymphedema after treatment of breast cancer. Am J Surg 2004;187:69-72.

14 Tengrup I, Tennvall-Nittby L, Christiansson I, Laurin M. Arm morbidity after breast-conserving therapy for breast cancer Acta Oncol 2000;39:393-7.

15 Shih YCT, Xu Y, Cormier JN, Giodarno S, Ridner SH, Buchholz TA. Incidence, teratment costs, and complications of lymphedema after breast cancer: a 2-year follow-up study. J Clin Oncol 2009;12:2001-14

16 Sander AP, Hajer NM, Hemenway K. Incidence and risk of arm oedema following treatment for breast cancer: a three-year follow-up study. Q J Med 2005;98:343-8.
17 Petrek J, Heelan M. Incidence of breast carcinoma-related lymphedema. Cancer 1998;83:2776-81.

18 Johansson K, Ohlsson K. Factors associated with the development of arm lymphedema following breast cancer treatment: a match pair case-control study. Lymphology 2002;35:59-71.

19 Martínez I, Torres M, Muñoz V, Mayoral O, Martín S. Informe Proyecto de Investigación: Eficacia del drenaje linfático manual y/o tratamiento farmacológico con benzopironas en la prevención del linfedema postmastectomía. Ensayo Clínico Randomizado a Simple Ciego. http://pid.ics.jccm.es/PaginasWeb/VisualizarProyecto.aspx? projectid=98267.In: Junta de Comunidades de Castilla La Mancha, Universidad Castilla La Mancha, 1999. [Report No 98267.$]$

20 Coen J, Taghian A, Kachnic L, Assaad S, Powel S. Risk of lymphedema after regional nodal irradiation with breast conservation therapy. Int J Radiat Oncol Biol Phys 2003;55:1209-15.

21 Koak Z, Overgaard J. Risk factors of arm lymphedema in breast cancer patients. Acta Oncol 2000;39:389-92.

22 McTiernan A. Obesity and cancer: the risks, science, and potential management strategies. Oncology 2005;19:871-81.

23 Nardone L, Palazzoni G. Impact of dose and volume on lymphedema. Rays 2005;30:149-55.

24 Meeske K, Sullivan-Halley J, Smith A, McTiernan A, Baumgartner K, Harlan $\mathrm{L}$, et al. Risk factors for arm lymphedema following breast cancer diagnosis in black women and white women. Breast Cancer Res Treat 2008;14:982-91.

25 Soerjomataram I, Louwman W, Ribot J, Roukema J, Coebergh J. An overview of prognostic factors for long-term survivors of breast cancer. Breast Cancer Res Treat 2008;107:309-30.

26 Weir H, Thun M, Hankey B, Ries L. Annual report to the nation on the status of cancer 1975-2000, featuring the uses of surveillance data for cancer prevention and control. I Natl Cancer Inst 2003;95:1276-98

27 Bani H, Fasching P, Lux M, Rauh C, Willner M, Eder I, et al. Lymphedema in breast cancer survivors: assessment and information provision in a specialized breast unit. Patient Educ Couns 2007;66:311-8.

28 Ridner S. Pretreatment lymphedema education and identified educational resources in breast cancer patients. Patient Educ Couns 2006;61:72-9.

29 Stout Gergich N, Pfalzer L, McGarvey C, Springer B, Gerber L, Soballe P. Preoperative assessment enables the early diagnosis and successful treatment of lymphedema. Cancer 2008;112:2809-18.

30 Box R, Reul-Hirche H, Bullock-Saxton I, Furnival C. Physiotherapy after breast cancer surgery: results of a randomised controlled study to minimise lymphedema. Br Cancer Res Treat 2002;75:51-64.

31 Epidat 3.1. Análisis epidemiológico de datos tabulados. In: A Coruña: Xunta de Galicia, 2006. http://dxsp.sergas.es/default.asp.

32 Ferrandez J, Serin D. Rééducation et cancer de sein. 2 edn. Elsevier Masson SAS, 2006.

33 Romay H. Caso clínico 10: miembro superior edematizado. In: Torres M, Salvat I, eds. Guía de masoterapia para fisioterapeutas. Médica Panamericana, 2006:311-20.

34 Torres M. Drenaje linfático manual. In: Torres M, Salvat I, eds. Guía de masoterapia para disioterapeutas. Médica Panamericana, 2006:239-67

35 Salvat I. Masaje. Maniobras básicas. In: Torres M, Salvat I, eds. Guía de masoterapia para fisioterapeutas. Médica Panamericana, 2006:152-9.

36 Neiger H, Gosselin P, Torres M. Estiramientos analíticos manuales. Médica Panamericana, 1998.

37 Adler SS, Beckers D, Buck M. La facilitación neuromuscular propioceptiva en la práctica. Guía ilustrada. 2nd edn. Médica Panamericana, 2002.

38 Ferrandez J, Piollet I, Serin D. Comment éduquer utilement une patiente opérée d'un cancer de sein à la prevention de son lymphoedème. Être utile sans nuire à la qualité de vie. Ann Kinésithér 1999;26:265-9.

39 Runowick C. Lymphedema: patient and provider education. In: American Cancer Society lymphedema workshop. American Cancer Society, 1998:2874-6.

40 Chen YW, Tsai HJ, Hung HC, Tsauo JY. Reliability study of measurements for lymphedema in breast cancer patients. Am J Phys Med Rehabil 2008;87:33-8.

41 Ferrandez JC, Serin D, Bouges S. Fréquence des lymphoedèmes de membre supérieur après traitement du cancer de sein. Facteur de risque. À propos de 683 observations. Bull Cancer 1996;83:989-95.

42 Harris S, Hugi M, Olivotto I, Levine M. Clinical practice guidelines for the care and treatment of breast cancer: Lymphedema. Can Med Assoc / 2001;164:191-9.

43 Hayes S, Battistutta D, Newman B. Objective and subjective upper body function six months following diagnosis of breast cancer. Breast Cancer Res Treat 2005;94:1-10.

44 Armer JM, Stewart BR. A comparison of four diagnostic criteria fo lymphedema in a post-breast cancer population. Lymphat Res Biol 2005;3:208-17. 
45 Ferrandez J, Bourassin A, Debeauquesne A, Philbert C. Étude prospective ambulatoire multipraticien du lymphoèdeme du membre supérieur après cancer de sein. À propos de 76 cas. Oncologie 2005;7:316-22.

46 Pourquier H, Giacalone PL, Laffargue F. La prise en charge postopératoire immédiate des femmes après chirurgie néoplasique mammaire. Un étude de kinésithérapie en milieu hospitalier. In Petiot S, Hérisson C, Pélissier J, eds. Cancer du sein traité et médecine de rééducation. Elsevier-Masson, 2007:46-68.

47 Karges J, Mark B, Stikeleather S, Worrell T. Concurrent validity of upper extremity volume estimates: comparison of calculated volume derived from girth measurements and water displacement. Phys The 2003;83:134-45.

48 Taylor R, Jayasingue U, Koelmeyer L, Ung O, Boyages J. Reliability and validity of arm volume measurements for assessment of lymphoedema. Phys Ther 2006;86:205-14.

49 Torres M, Yuste MJ, Prieto D. Estudio de fiabilidad y reproducibilidad de las medidas cirtométricas en miembro superior e inferior sanos. Cuest fisioter 2010;39(in press).

50 Ferrandez JC, Doyer M, Serin D, De Rauglaudre G. Thromboses lymphatiques superficielles. In: Petiot S, Hérisson C, Pélissier J, eds. Cancer du sein traité et médecine de rééducation. Elsevier-Masson, 2007:119-28.

51 Torres Lacomba M, Mayoral del Moral O. Les thromboses lymphatiques superficielles à l'origine du syndrome douloureux myofascial après curage axillaire pour cancer du sein. Kinésither Scient 2008;494:25-8.

52 Torres M. Caso clínico 13: dolor en la cara medial del brazo. In: Torres M, Salvat I, eds. Guía de masoterapia para fisioterapeutas. Médica Panamericana, 2006:337-42.

53 Torres M, Cerezo E. Actuación fisioterapéutica en la trombosis linfática superficial tras cirugía mamaria con linfadenectomía. A propósito de un caso. Cuest fisioter 2009;38:170-8.

54 Torres Lacomba M, Mayoral del Moral O, Coperias Zazo JL, Ferrandez JC, Zapico Goñi A. Axillary web syndrome after axillary dissection in breast cancer: a prospective study. Breast Cancer Res Treat 2009;doi:10.1007/s10549-009-0371-8.

55 Cheville AL, McGarvey C, Petreck JA, Russo SA, Hiadens SRJ, Taylor ME. The grading of lymphedema in oncology clinical trials Semin Radiat Oncol 2003;13:214-25.

56 Kosir MA, Rymal C, Koppolu C, Hryniuk L, Draga L, Du W. Surgical outcomes after breast cancer surgery: measuring acute lymphedema. J Surg Res 2001;95:147-51.

57 STATA software (10.0 version). StataCorp, 2008.
58 Tobbia D, Semple J, Baker A, Dumont A, Semple A, Johnston M. Lymphedema development and lymphatic function following lymph node excision in sheep. J Vasc Res 2009;46:426-34.

59 Ferrandez JC, Serin D, Vinot JM, Felix Faure C. Évaluation linfoscintigraphique de la technique du drainage lymphatique manuel. À propos de l'exploration de 47 lymphoèdemes secondaires du membre supèrieur. Ann Kinésithér 1995;22:253-62.

60 Földi M, Strössenreuther R. Principes du drainage lymphatique. Maloine, 2005.

61 Leidenius M, Leppanen E, Krogerus L, von-Smitten K. Motion restriction and axillary web syndrome after sentinel node biopsy and axillary clearance in breast cancer. Am J Surg 2003;185:127-30.

62 Moskovitz A, Anderson B, Yeung R, Byrd D, Lawton T, Moe R. Axillary web syndrome after axillary dissection. Am J Surg 2001;181:434-9.

63 Ferrandez JC, Torres M. El drenaje linfático manual de la extremidad inferior: guía para una aplicación actual. Cuest fisioter 2008;37:187-93.

$64 \mathrm{Na}$ Y, Lee J, Park J, Kang S, Lee H, Koo J. Early rehabilitation program in postmastectomy patients. Yonsei Med J 1999;40:1-8.

65 Le Vu B, Dumortier A, Guillaume M, Mouriesse H, Barreau-Pouhaer L. Efficacité du massage et de la mobilisation precoces du membre superieur après traitement chirurgicale pour cancer de sein. Bull Cancer 1997;84:957-61.

66 Kilbreath SL, Refshauge KM, Beith JM, MiJoung L. Resistance and stretching shoulder exercises early following axillary surgery for breast cancer. Rehabil Oncol 2006;24:9-14.

67 Çinar N, Seçin U, Keskin D, Bodur H, Bozkurt B, Cengiz O. The effectiveness of early rehabilitation in patients with modified radical mastectomy. Cancer Nurs 2008;31:160-5.

68 Todd J, Scally A, Dodwell D, Horgaan K, Topping A. A randomised controlled trial of two programmes of shoulder exercise following axillary lymph node dissection for invasive breast cancer. Physiotherapy 2008;94:265-73.

69 Földi E, Földi M. The lymphoedema chaos: a lancet. Ann Plast Surg 1989;22:505-15.

70 Hack TF, Coen L, Katz J, Robson P, Goss P. Physical and psychological morbidity after axillary lymph node dissection for breast cancer. J Clin Oncol 1999;17:143-9.

71 Shamley DR, Barker K, Simonite V, Beardshaw A. Delayed versus immediate exercises following surgery for breast cancer: a systematic review. Br Cancer Res Treat 2005;90:263-71.

Accepted: 9 October 2009 